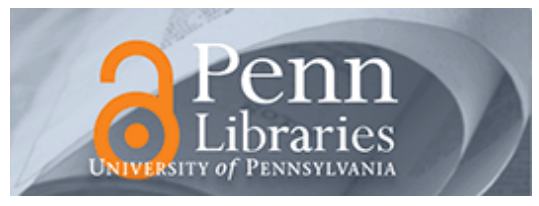

University of Pennsylvania

ScholarlyCommons

$1-19-2018$

\title{
Association of Patient Out-of-Pocket Costs With Prescription Abandonment and Delay in Fills of Novel Oral Anticancer Agents
}

Jalpa A. Doshi

University of Pennsylvania, jdoshi@mail.med.upenn.edu

Pengxiang Li

University of Pennsylvania, penli@mail.med.upenn.edu

Amy R. Pettit

Katrina A. Armstrong

Massachusetts General Hospital

Follow this and additional works at: https://repository.upenn.edu/ldi_researchbriefs

Doshi, Jalpa A.; Li, Pengxiang; Pettit, Amy R.; and Armstrong, Katrina A.. Association of Patient Out-ofPocket Costs With Prescription Abandonment and Delay in Fills of Novel Oral Anticancer Agents. LDI Research Briefs. 2018; No. 33. https://ldi.upenn.edu/brief/association-patient-out-pocket-costsprescription-abandonment-and-delay-fills-novel-oral

">

https://ldi.upenn.edu/brief/association-patient-out-pocket-costs-prescription-abandonment-and-delayfills-novel-oral

This paper is posted at ScholarlyCommons. https://repository.upenn.edu/ldi_researchbriefs/33

For more information, please contact repository@pobox.upenn.edu. 


\title{
Association of Patient Out-of-Pocket Costs With Prescription Abandonment and Delay in Fills of Novel Oral Anticancer Agents
}

\begin{abstract}
High out-of-pocket (OOP) costs may limit access to novel oral cancer medications. In a retrospective study, nearly one third of patients whose OOP costs were $\$ 100$ to $\$ 500$ and nearly half of patients whose OOP costs were more than $\$ 2,000$ failed to pick up their new prescription for an oral cancer medication, compared to $10 \%$ of patients who were required to pay less than $\$ 10$ at the time of purchase. Delays in picking up prescriptions were also more frequent among patients facing higher OOP costs.
\end{abstract}

\section{Keywords}

out-of-pocket costs, cancer, prescription, coinsurance, delay, abandonment

\section{License}

(c) (1) (2)

This work is licensed under a Creative Commons Attribution-No Derivative Works 4.0 License. 
DATA DRIVEN.POLICY FOCUSED

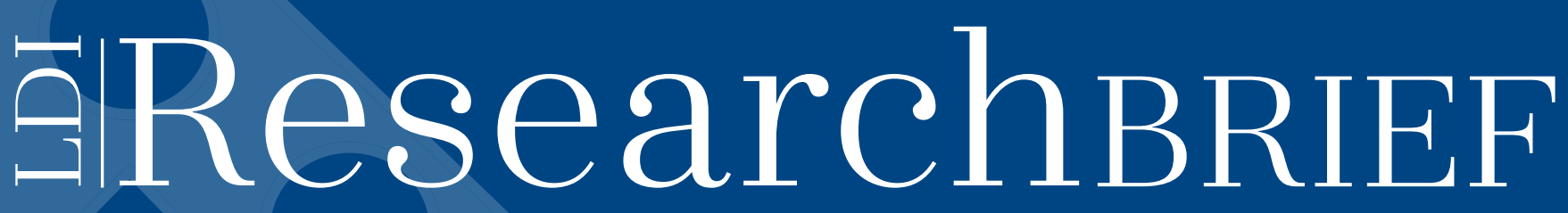

\title{
ASSOCIATION OF PATIENT OUT-OF-POCKET COSTS WITH PRESCRIPTION ABANDONMENT AND DELAY IN FILLS OF NOVEL ORAL ANTICANCER AGENTS
}

\author{
Jalpa A. Doshi, Pengxiang Li, Hairong Huo, Amy R. Pettit, and Katrina A. Armstrong
} Journal of Clinical Oncology - published online before print December 20, 2017

\section{KEYFINDINGS}

High out-of-pocket (OOP) costs may limit access to novel oral cancer medications. In a retrospective study, nearly one third of patients whose OOP costs were $\$ 100$ to $\$ 500$ and nearly half of patients whose OOP costs were more than $\$ 2,000$ failed to pick up their new prescription for an oral cancer medication, compared to $10 \%$ of patients who were required to pay less than $\$ 10$ at the time of purchase. Delays in picking up prescriptions were also more frequent among patients facing higher ○९ costs.

\section{THE QUESTION}

The number of novel oral anticancer therapies has increased considerably in recent years, often accompanied by a high price tag. Due to an increase in high-deductible health plans and growing use of specialty tiers with coinsurance (as opposed to fixed copayment) requirements, many cancer patients face high out-of-pocket (OOP) costs for these medications. Because patients must pay the entire $\bigcirc \mathrm{P}$ cost for an oral prescription up front, these costs present a unique risk that patients will delay pick-up of the prescription or opt not to fill it at all.

To better understand how these costs affect the initiation of novel treatments, the authors analyzed claims data for patients covered by commercial insurance or Medicare Part D who received a new prescription for any of 38 oral anticancer medications from 2014-2015. These claims data were unique in that they included all prescriptions approved by the payer, including those that the patient opted not to fill, along with the amount due from the patient at the time of pickup after coupons or copayment assistance were applied.

\section{THE FINDINGS}

Among 38,111 patients, the average $\bigcirc \mathrm{OP}$ cost was $\$ 486$; overall, $18 \%$ of patients "abandoned" their index prescription, meaning that they did not pick up an insurer-approved prescription for the index medication within 90 days. On average, patients who abandoned their prescription had higher mean OOP costs $(\$ 1,397)$ than those who filled it (\$284). Across OOP cost categories, few patients who abandoned their prescription went on to have prescription claims for alternate cancer treatments, including intravenous therapies, in the following 90 days.

Adjusting for socioeconomic and clinical characteristics, the authors found that rates of abandonment and delay increased as the OOP cost category increased, in a linear fashion. As shown in Figure 1, nearly half of patients (49\%) facing $\bigcirc \mathrm{OP}$ costs over $\$ 2,000$ abandoned their prescription, whereas only $10 \%$ of patients facing $\mathrm{OP}$ costs of less than $\$ 10$ did. Among patients in the lowest $\bigcirc \bigcirc \mathrm{P}$ cost category, only 3\% delayed filling their prescription, compared with $18 \%$ in the highest OOP cost category. The average delay was 35 days, which was similar across all Ю०P cost categories. 


\section{ResearchBRIEF}

\section{FIGURE 1}

PRESCRIPTION ABANDONMENT AND DELAY IN FILLS OF ANTICANCER AGENTS

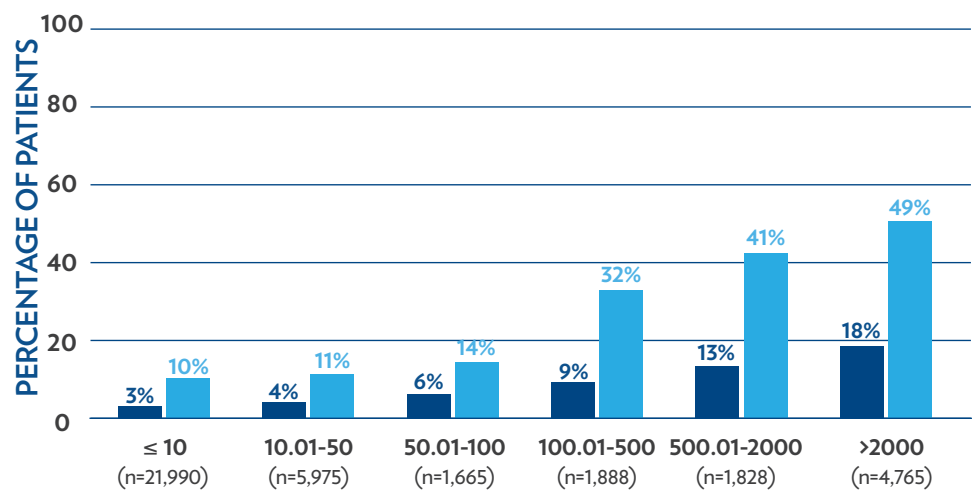

OUT-OF-POCKET COST CATEGORY (\$)

- Delay Abandonment

These patterns were consistent across cancers. Although abandonment rates were highest for medications to treat metastatic cancers that typically have poorer prognosis, a substantial percentage of patients abandoned treatment even for cancers where the medication has been shown to extend life by many years.

The authors used these risk-adjusted rates to simulate how abandonment might change in light of ongoing trends toward higher O०P costs. This simulation revealed that if patients currently responsible for $\$ 50$ to $\$ 100$ per prescription were shifted to the next higher OOP cost category ( $\$ 100$ to $\$ 500$ ), abandonment rates would likely double (from 16\% to 36\%).

\section{THE IMPLICATIONS}

This study raises questions about whether patients will be able to take advantage of new cancer treatments. Currently, O०P costs greater than $\$ 2,000$ for a new oral cancer medication are typical for Medicare Part D patients without low-income subsidies and for many commercially insured patients. Given the study's focus on new treatment episodes, these findings suggest that financial barriers may limit patient access to what may be the provider's and/or patient's first choice medication. Such obstacles may impose additional financial burdens and inflict emotional stress at a time when patients are already coping with a life-altering diagnosis or change in medical status.
The findings also point to the need for timely patient-provider conversations to evaluate any alternate, lower OOP cost treatment options. This is especially important with self-administered treatments, where initiation delay and nonadherence are more difficult to monitor. As the availability of oral anticancer treatment options continues to increase, access and affordability will determine the true benefit for patients. All stakeholders - including manufacturers, pharmacy benefit managers, payers, and policymakers - must work to identify fiscally sustainable strategies to improve patient access to cancer medications.

\section{THE STUDY}

This retrospective, claims-based analysis used data from a large, proprietary, integrated database that includes point-of-sale prescription purchase information detailing the patient's ЮОP liability (after application of coupons or copay assistance) and final claim payment status (paid or reversed claim)

The final sample included 38,111 patients with a new, payer-approved prescription for any of 38 oral anticancer medications between 2014-2015. The authors tracked whether patients filled their prescription after it was approved by the insurer, and if not (i.e., the claim was reversed), whether the prescription was filled with a delay (within 90 days) or abandoned completely. The authors also examined whether patients who abandoned their prescription initiated alternate treatment from the same drug class, including intravenous therapies, in the following 90 days. They adjusted for other relevant factors, including type of insurance, type of pharmacy, and patient characteristics, and explored differences for several patient subgroups (by insurance coverage, pharmacy type, sex, and indication).

Doshi, Jalpa A., Pengxiang Li, Hairong Huo, Amy R. Pettit, and Katrina A. Armstrong, Association of Patient Out-ofPocket Costs With Prescription Abandonment and Delay in Fills of Novel Oral Anticancer Agents. Journal of Clinical Oncology. 2017. doi: 10.1200/JCO.2017.74.5091

LDI Research Briefs are produced by LDl's policy team. For more information please contact Janet Weiner at weinerja@pennmedicine.upenn.edu.

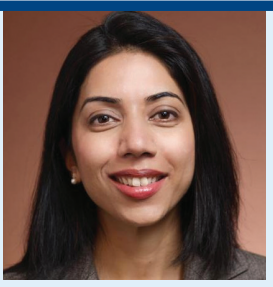

\section{LEAD AUTHOR}

\section{DR. JALPA DOSHI}

Jalpa Doshi, PhD is Professor of Medicine at Penn's Perelman School of Medicine. Her research examines the impact of prescription benefit design and reimbursement policies on access to prescription drugs, and the quality and cost of health care in vulnerable patient populations, including elderly, disabled, chronically ill and low-income patients. Dr. Doshi is Director of Value-Based Insurance Design Initiatives at the Center for Health Incentives and Behavioral Economics and Director of the Economic Evaluations Unit of the Center for Evidence-Based Practice at the University of Pennsylvania Health System. 